\title{
ROAD SAFETY AWARENESS AMONG UNIVERSITY STUDENTS: CASE STUDY AT MALAYSIA UNIVERSITI TUN HUSSEIN ONN MALAYSIA, JOHOR
}

\author{
R. Abd Rahman ${ }^{1 *}$, H. A. Mazle ${ }^{1}$, W. M. Lim ${ }^{1 *}$, M. I. Mohd Masirin ${ }^{1}$ and M. F. Hassan ${ }^{2}$ \\ ${ }^{1}$ Faculty of Civil and Environmental Engineering, Universiti Tun Hussein Onn Malaysia, 86400 Parit Raja, Batu \\ Pahat, Johor, Malaysia \\ ${ }^{2}$ Pejabat Setiausaha Kerajaan Johor, Bahagian Perumahan, 79503 Iskandar Puteri, Johor, Malaysia
}

Date received: 05/03/2021 Date accepted: 15/03/2021

*Corresponding author's email: raha@uthm.edu.my, limweimay@gmail.com

DOI: $10.33736 /$ jcest.3344.2021

\begin{abstract}
This descriptive study aims to assess the knowledge and awareness of road safety among university students. The study was conducted among students in Universiti Tun Hussein Onn Malaysia by means of questionnaire disseminated online via social media with shareable link to a Google form. The respondents were self-selected to participate in this study where their responses were self-administrated. Questionnaire consisted of 3 sections included demographic information, knowledge on road signs and road safety law, and road safety awareness. 371 students participated in this study, $66 \%$ of them age 23 to 27 years old, $61 \%$ were female, $92.5 \%$ of respondents have at least one type of license with majority agreed that occurrence of accidents resulted in an increase in road safety awareness. The study found that more than half of the participants could not recognise road sign like parking totally prohibited and speed limit ends here. While, $38 \%$ of them correctly identified posted speed limit for expressway. Overall, participants have fair understanding on road safety. Therefore, road safety programmes and education are still relevant to university students as young drivers on the road which is important to increase safety awareness.
\end{abstract}

Copyright (C) 2021 UNIMAS Publisher. This is an open access article distributed under the Creative Commons Attribution-NonCommercial-ShareAlike 4.0 International License which permits unrestricted use, distribution, and reproduction in any medium, provided the original work is properly cited.

Keywords: Road Safety, Awareness, Knowledge, University Students

\subsection{INTRODUCTION}

Road accidents can happen unexpectedly and unintentionally, it is important to identify the causes behind occurrence of road accidents to prevent them from becoming norm of our daily lives. The concern on increasing trend of road accidents lead to the importance of studying road safety. Road safety is methods or measures taken to enhance safety for road users and preventing them from fatality. The 3 contributing factors to road accidents are human, environment and vehicles. Preventions are road safety actions taken as countermeasure considering these three contributing factors include educational programmes, campaigns, advertisements, law enforcements, development of safety features in road infrastructure and development of safety system in vehicles. Authority has taken a lot of efforts conducting the said preventions to promote awareness on road safety. The question is, are these efforts adequate to highlight the importance of road safety to prevent fatality from occurring among university student in this context, UTHM students? This study focuses on UTHM students who are community of young drivers who travel with varies mode of transportation.

\subsection{OBJECTIVES}

The purpose of this study is to find out the level of awareness of road safety among University Tun Hussein Onn Malaysia (UTHM) students. For this purpose, the following objectives are set:

- to assess the knowledge of road safety among students; and

- to evaluate the level of awareness by using questionnaire. 


\subsection{LITERATURE REVIEW}

There are varies studies on road safety awareness and compliance among different group of people in different locations such as on road users at U-turns [1], [2], at school zones [3], among youth in Al-Ahsa region in Saudi Arabia [4], among undergraduate students [5], among undergraduate medical students of Al-Baha University KSA [6], among school children of Chandigarh [7]. This previous study found that road users understand the significant to practice road safety but failed to comply with the practice due to habitual behaviour. Abdo and Ibrahim [8] states that the common offences road users did but knowing are wrong are speeding and usage of mobile phone while driving. The study also found that participants are knowledgeable in traffic offices but weak in traffic regulations and signs. Hence, the study recommended that traffic safety awareness coupled with traffic regulations to be promoted intensively for better compliance with road safety practice.

Traffic accidents are the major cause of over an estimated of 1.24 million deaths worldwide according to World Health Organizations (WHO). Half of the number is among the pedestrians, cyclists and motorcyclists, adults aged between 15 to 44 years old and according to WHO. Road traffic injuries (RTIs) are the second most significant cause of death for kids at the age of 5 years old up to 29 years old [9], [10]. Road safety should be taken more seriously, and road safety awareness should be emphasised because practicing safe road usage can save lives especially among youths who are still new and inexperience to driving.

Human behaviour is highest contributing factor of road accidents as shown in Figure 1. While, road accidents are one of the main causes of fatality across the world. Driving attitudes such as speeding, road rage, fatigue, driving under influence are some of the human behaviours that lead to road accidents fatalities. Speeding can cause serious injury or worse, fatality is because the time taken to response to impact during traffic accident to occur is shorter and chances of being safe largely reduced [3]. Hence, this study is set to identify some of the habits that university students do which are traffic offences. As well as some of the awareness and educational programmes can be done to emphasize road safety among university students.

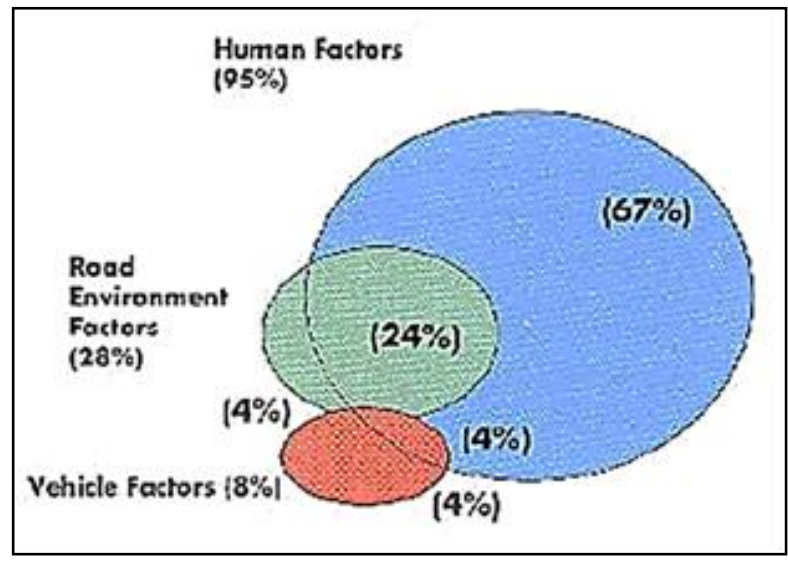

Figure 1 Factors contributing to road accidents. Source [11]

\subsection{SAMPLE SIZE OF STUDY, N}

A literature research is done in order to assist the method of obtaining the sample size, $\mathrm{N}$ of our given data population. According to [12] a table of sample size, $\mathrm{N}$ according to respective population for example the total population of 12186 for UTHM the suitable sample size is $\mathrm{N}=370$. 
Cronbach alpha is to provide a measure of internal consistency of a test or a scale in a decimal number of 0 to 1 . It is also to determine the reliability of a study. Internal consistency is a description of how far the parameters in the test measure a consistent concept to one another [13]. It is important to use a correct alpha that is related to our study so that the result obtained later is reliable. According to [14], 0.70 is the standard alpha value to be used to measure reliability of a study while the highest value of alpha is 0.9 . A low value of alpha may indicate that there is low consistency among the questions in a questionnaire which show poor correlation between the items. In the other hand, a very high value of alpha may indicate that there is a very high correlation between the items, such as several question that highlighted the same theme of question with a different structure of sentences.

However, there are certain exception involving the value of Cronbach alpha to indicate the reliability of questionnaire. There are several research papers that support the value other than 0.7 for the reliability test and normally the value is much lower than 0.7 such as 0.6-0.7 is already acceptable for Cronbach alpha [15]. This is due to the differences in the structure of questionnaire in order to achieve respective study objective. These differences develop other Cronbach alpha indicator which is 'Cronbach alpha based on standardised items. Cronbach alpha based on standardised items is used if the structure of questionnaire contains several changes in response option. Hence, a good Cronbach alpha value is based on the suitability of analysing the obtained responses of particular questionnaire.

\subsection{PILOT STUDY}

According to [16] states that, conducting pilot test is important as it can increase the likelihood of success of a certain research or study as it can show the estimation of the desire results. This will help to examine the practicality and feasibility of the methods to be used in a subsequent larger and more comprehensive investigation. Pilot test is needed to gain early estimation of the result to locate any bias result from respondents. From there, we can know either the questionnaire can be used or not for this study. The quantity of respondents for pilot test is 10 to $20 \%$ of sample size, $\mathrm{N}$.

\subsection{METHODOLOGY}

Online questionnaire was used as the study instrument to collect data due to time constraint. The questionnaire was disseminated via social media where the respondents were self-selected to participate in the study. The responses are collected via Google form. There 3 sections in the questionnaire to achieve the study objectives. Section A is on the background of the respondents. Section B is to determine the respondent's knowledge of road signs and understanding on road law and regulations. Section $\mathrm{C}$ is to determine the respondents understanding on road safety awareness and habits. The questionnaire is designed with closed-ended true or false and multiple choices questions to test knowledge-based facts where respondents were to pick an answer for each question. Pilot test was conducted with 40 respondents in the reliability test before the questionnaire is released for the study. All the data is analysed using SPSS 21 software to obtain the Cronbach alpha value and the percentage of responses from each question.

\subsection{STUDY LOCATION AND RESPONDENTS}

Location of study is at main campus of UTHM at Batu Pahat, Johor with a population of 12186 university students. Based on Krejcie \& Morgan table, a sample size of 370 respondents is sufficient.

\subsection{RESULTS AND DISCUSSIONS}

The result of pilot test revealed that Cronbach alpha based on the standardized items for the first set of the questionnaire was 0.4 which is insufficient. Then, a few amendments for the questionnaire were done according to what was suggested using the software such as deleting a few unnecessary questions in order to gain a much higher Cronbach alpha. After that, a new questionnaire was again spread among UTHM students and another pilot test was done. The new Cronbach alpha was 0.59 and according to [15], this 
value was sufficient and therefore the questionnaire's reliability was confirmed. After successfully passing the reliability test, the final questionnaire was spread out until more than 370 respondents were recorded. As shown in Table 1 below, final result for the Cronbach alpha reliability test is 0.64 . Before analysing the results, filtration processes were carried out in order to avoid processing an error answer from the questionnaire such as an incomplete form of answer.

Table 1 Reliability statistics

\begin{tabular}{cccc}
\hline Cronbach's Alpha & Cronbach's Alpha Based on Standardized Items & N of Items \\
\hline 0.230 & 0.64 & 55 \\
\hline
\end{tabular}

The final analysis for the online questionnaire consisted a total of 371 respondents, which is sufficient according to the sample size $S$ that this study is required. Majority of the respondents was from the age of 23 to 27 years old with a percentage of $66 \%$. Followed by 18 to 22 years old of $29 \%$. While, only a very small percentage is from age 28 to 32 years old and above 33 years old of $3 \%$ and $2 \%$ respectively as shown in Table 2. Respondents from the age group of 23 to 27 years old are students in their third and final year in university where they are allowed to bring in their vehicles to the campus. Figure 2 shows the study had a higher record of female respondents of 226 students. While, male respondents at 145 students.

Table 2 Age of participants

\begin{tabular}{cc}
\hline Age & Participants \\
\hline $18-22$ & $29 \%$ \\
$23-27$ & $66 \%$ \\
$28-32$ & $3 \%$ \\
33 and above & $2 \%$ \\
\hline
\end{tabular}

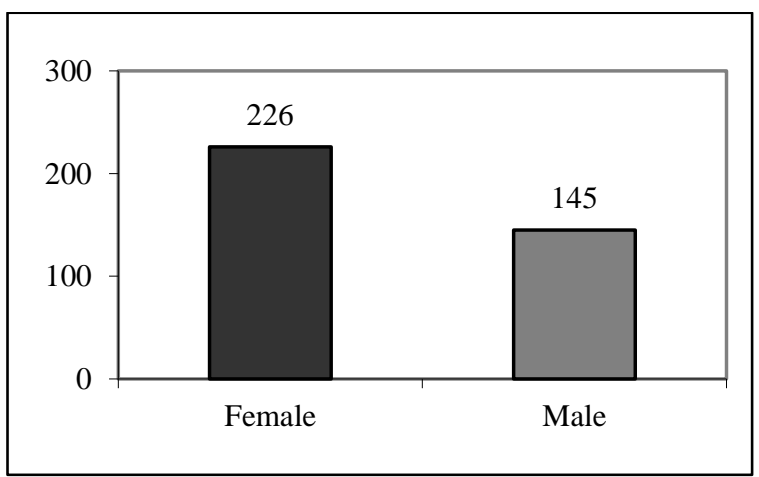

Figure 2 Gender of participants

In Section A, respondents were also asked on the type of driving license that they acquired and whether they experienced accidents before as road users. The results are illustrated in Figure 3. 


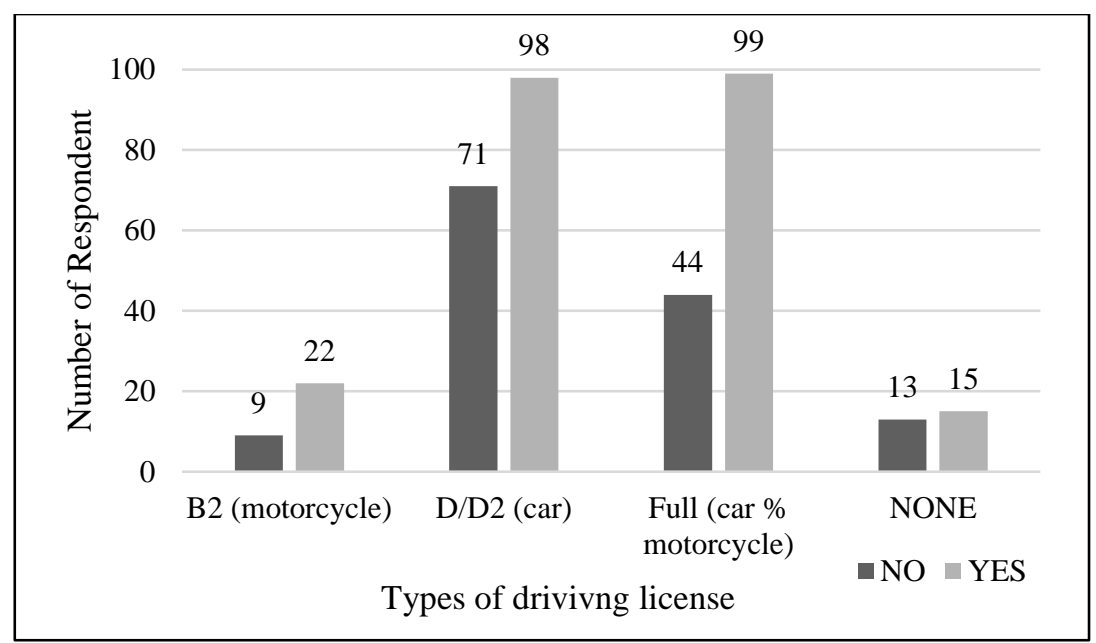

Figure 3 The relationship between the type of driving license owned by the respondents and the percentage of those who had experienced accident

Out of the 371 respondents, 31 respondents possessed B2 license, 169 respondents had D/DA license, 143 respondents had acquired license with both car and motorcycle, and the remaining 28 did not have any type of license. Majority of the respondents are with car license only which is D/DA license with the percentage of $46 \%$, followed by $38 \%$ of respondents with both car and motorcycle license. Among these two groups of respondents, 98 respondents that have only D/DA license have experienced an accident. While, 99 respondents that have full license have had an accident in the past. Those who did not possess any driving license, pedestrians and cyclists, remain as a minority group with only $4 \%$ of them had experienced an accident before. The last question in Section $\mathrm{A}$ is to determine if the experience of accidents had impacted the respondents to be more aware of road safety. Figure 4 illustrates the total percentage of respondents that agreed that accident experiences have an impact in increasing the awareness about road safety among them. A vast majority of the respondents constitutes of 345 students agreed that accident does give them awareness about the importance of road safety that need to be implemented daily to appreciate the value of lives.

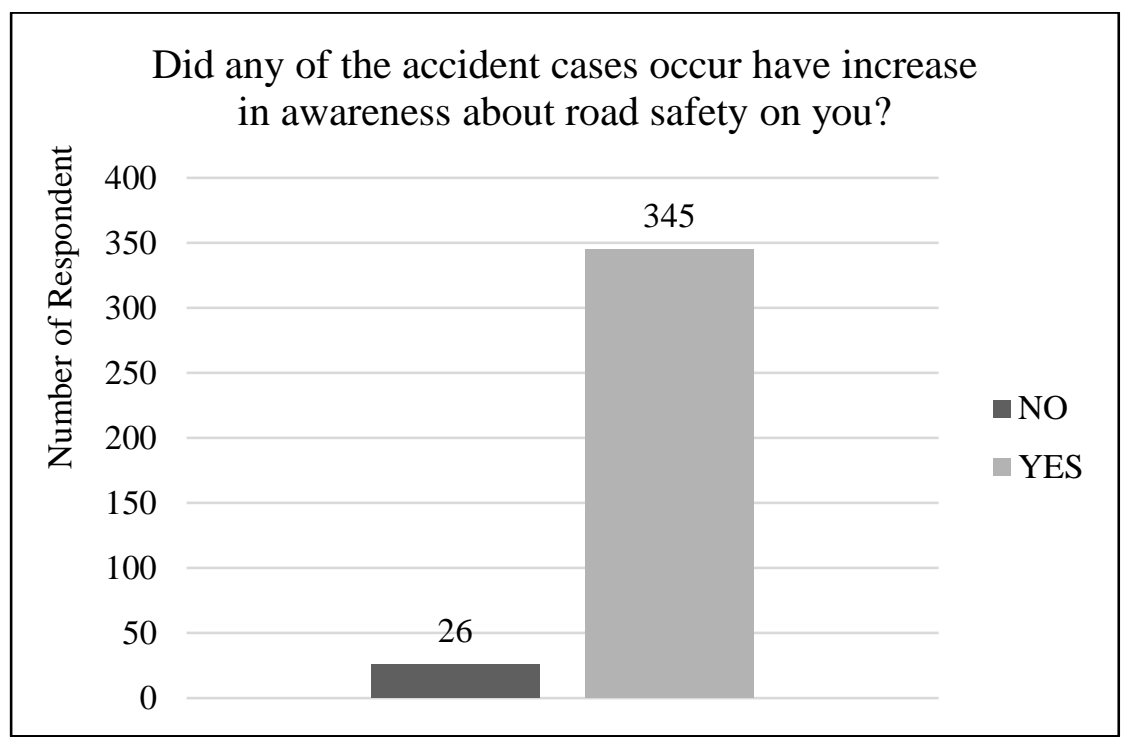

Figure 4 Percentage of increase in awareness in cases of accident

For Section B, results of analysis are shown in Figure 5. Among the road signs, speed limit ends here, and parking totally prohibited are the two road signs that respondents were not able to identify correctly with only $29 \%$ and $48 \%$ of the respondents know about these signs respectively. Gharaibeh and Abdo [4] found that accidents rate is high among young drivers because they are lacking of knowledge with road 
signs coupled with inexperience driving and incompliance with traffic regulations. Despite knowing the traffic offences, they still did the wrong driving practices such as speeding. Rahman et al. [3] road users are aware of speed limit in school zones and understand speed limit signs installed near the premises. However, actual driving on the road shows contradicting behaviour where the road users where driving beyond the speed limit. Nemmang et. al.[2] found that even with the posted traffic signs to warn of the danger, drivers tend to ignore the warnings and drive aggressively. Reckless driving such as speeding, red running, tailgating, sudden change of lanes and weaving are behaviours of inattentive drivers who are unable to obey speed limit signs [1]. Besides these road signs, road intersection and stopping totally prohibited are two road signs with above average score where $62 \%$ and $61 \%$ of respondents able to correctly identify. Stopping totally prohibited and parking totally prohibited are signs with colour and image that are lacking correlation with meaning or warning the signs are portraying. This is also the case for speed limit end here sign, if without prior education, this could be confusing to determine the meaning. Unlike the high score road signs such as stop at intersection (96\%); restriction on use of horn (99\%), turn right only (87\%), obstruction marker (81\%) and give way (91\%) where the image and colour truly portray the signs meaning it is to warn which can easily understand and identify.

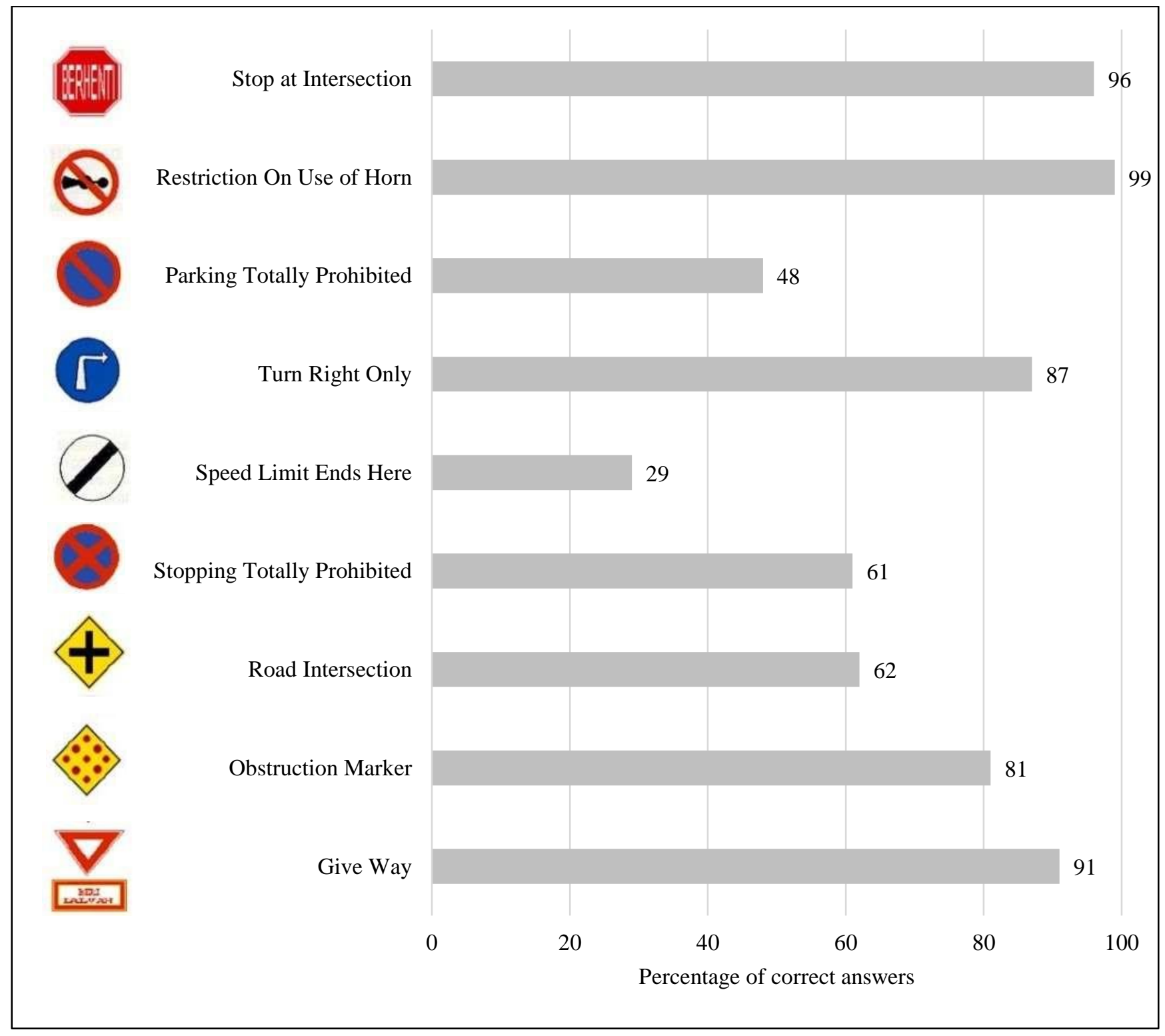

Figure 5 Percentage of correctly identified road signs by respondents 
As part of Section B, knowledge on road law and regulations of respondents are assessed and results are shown in Figure 6. Overall, respondents have basic understanding about road safety as majority manage to answer each of the statements correctly. Turning on hazard light during a rush or need to speed up is not allowed and $77 \%$ of respondents able to answer this statement correctly. Hazard lights are used to indicate the car is at stop. $88 \%$ of respondents know that overtaking in a double line road marking is not allowed. The act of stopping at emergency land at highway for rest is not allowed is known by $86 \%$ of the respondents. For motorcyclist, helmet is very important to protect riders from direct impact of accidents. This statement is agreed by $98 \%$ of respondents. $90 \%$ of the respondents agreed that road signs should be easily understand and functional. The position of ' $\mathrm{P}$ ' sticker is correctly identified by $86 \%$ of respondents. Only $66 \%$ of respondents know car restraint seat should be placed at the rear seat. $91 \%$ of respondents understand that yellow traffic light is when driver ready to stop. However, from the results, there are still minority of respondents who did not fully know some of the acts are traffic offences that will bring danger to their lives as well the lives around them such as respondents who disagreed that helmet is important (2\%), overtaking in double lane (125), resting in emergency land (14\%) and speed up during yellow light to beat red lights $(9 \%)$.

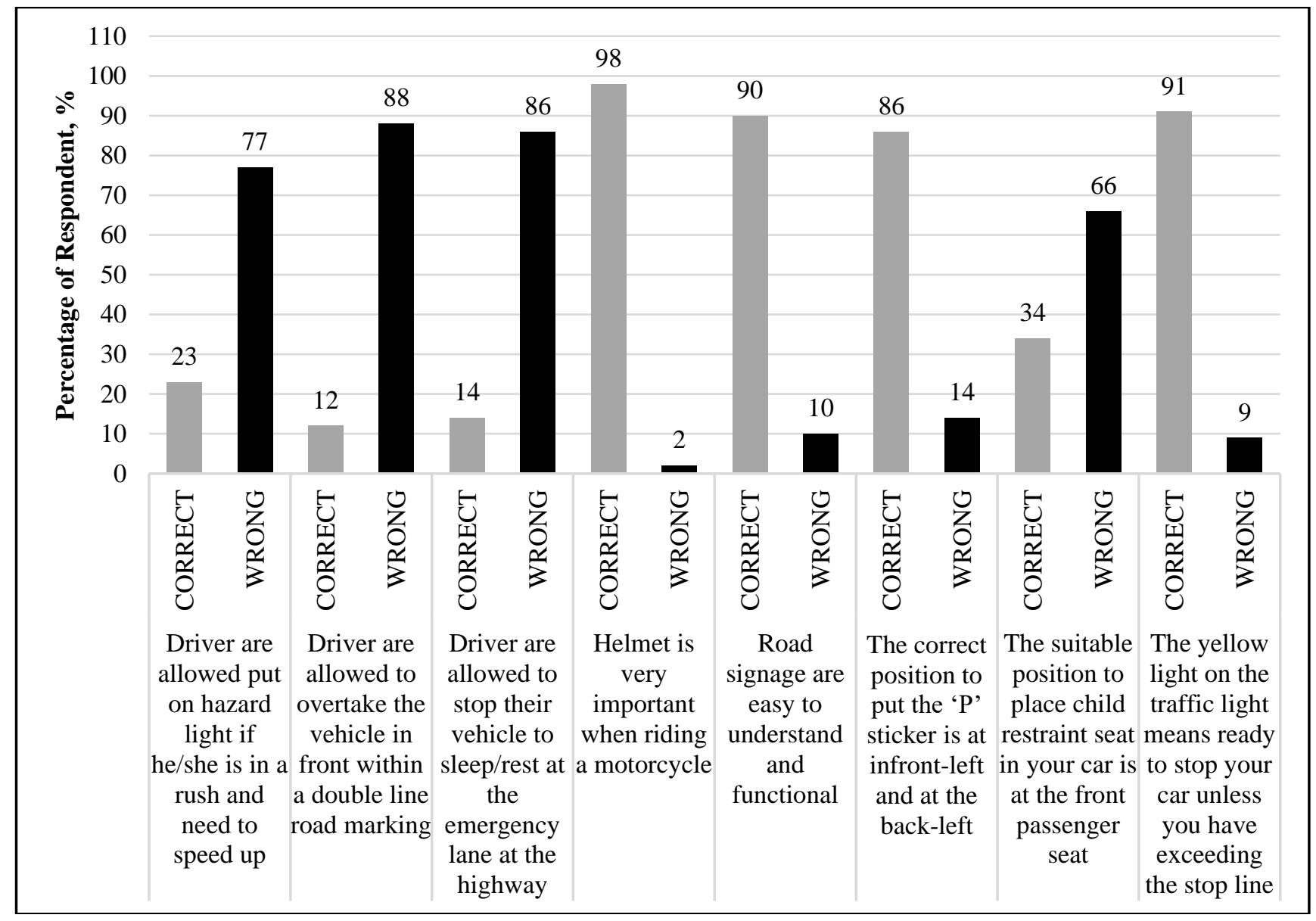

Figure 6 Knowledge on road law and regulations

Assessment on the responses for road safety awareness and habits are shown in Figure 7. 93\% of respondents know that road safety awareness is important among road users. $90 \%$ of respondents agreed that internet is a suitable media to be used to create awareness. While, lesser for road safety campaign agreed by $68 \%$ respondents. Only $26 \%$ of respondents agreed that language could be a form of barrier in spreading campaign about road safety awareness. Also, the result shows that $95 \%$ of respondents agreed that road safety should be taught as early as in primary school. $97 \%$ of respondents are more alert when there is presence of authority and $87 \%$ of them agreed that fines and penalties imposed are sufficient in helping them to avoid committing traffic offences. However, more than half of respondents admitted to the act of using mobile phone while driving and it is clearly deviate from supporting the importance of 
road safety awareness. Students often distracted by their devices for navigations $91 \%$ respondents and replying text massages $89 \%$ respondents. Whereas, $54 \%$ respondents practice putting on seatbelt while driving. Overall, there is lacking safety practice habits such as mobile phone usage while driving and not wearing seatbelts. In attempt to raise road safety awareness, internet is preferable medium especially in this digital age where youths are on their mobile devices. Besides, instead of road safety campaign, other means can be used to raise awareness as suggested in [17] the prevention of accidents covers these actions application of new technology and safety system in vehicles and road infrastructure, enforcement of regulations concerning road safety and education in road traffic safety to change the bad driving behaviours [18]-[20]. The community such as teachers and traffic police also plays an important role in inculcating traffic safety among students [7]. Besides, authority should be stricter especially offences of speeding and usage of mobile phone while driving [8]. Road safety programmes should focus on less knowledgeable road users with negative attitude towards seatbelts and speeding [10]. Behaviour concerning mobile phone and speeding are highly dangerous to the driver and public should be addressed by means of legislative and education [5].

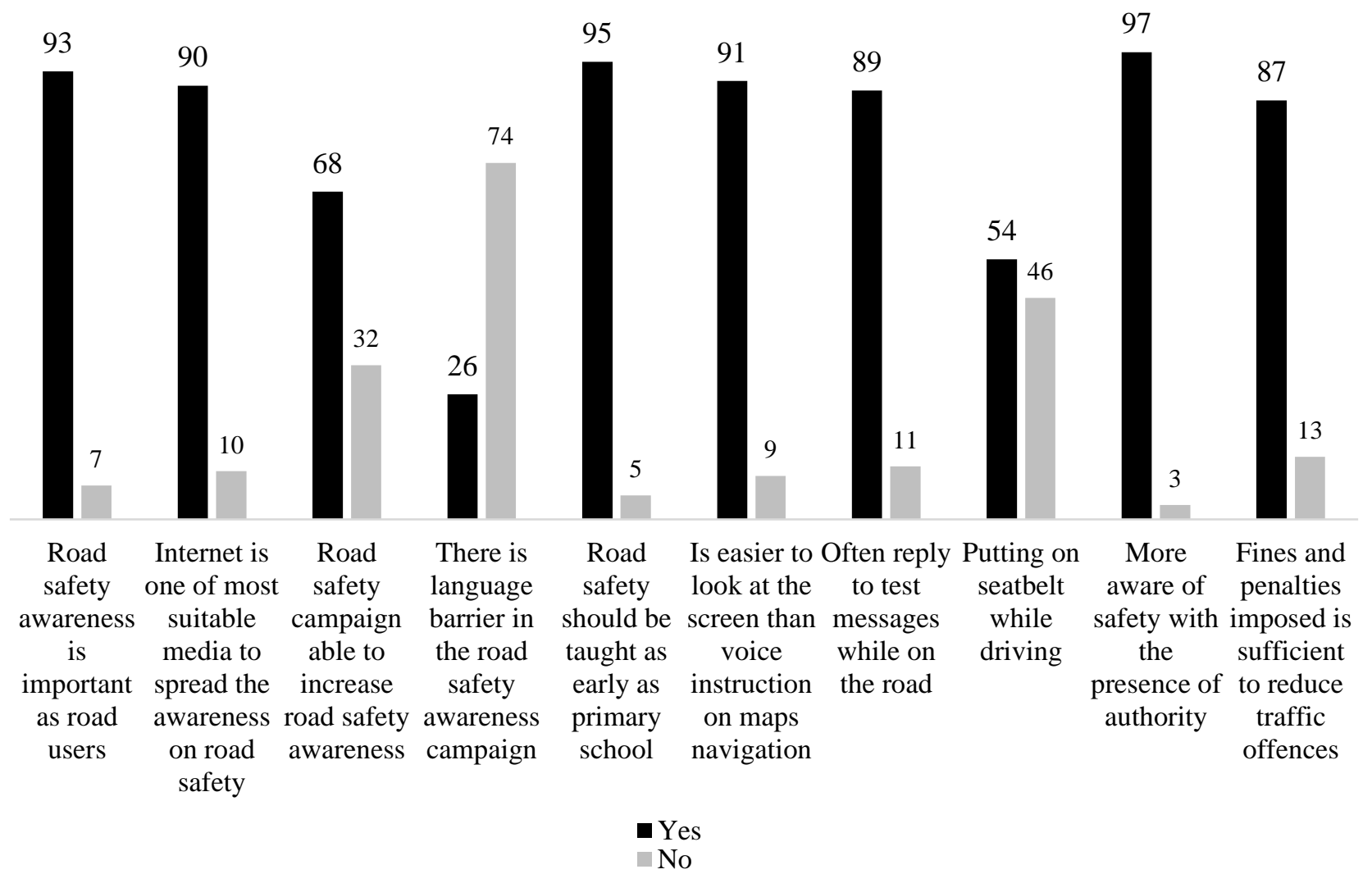

Figure 7 Road safety awareness and habits

\subsection{CONCLUSION}

Respondents of the study are university students who are youths and young drivers with few years of experience on the road and more than half of them had experienced accidents. They show moderate knowledge on road regulations, road signs, good road user habits and road safety awareness. Hence, it is important to increase their understanding and potentially reduce accidents due to human behaviour. There are some concerning traffic offences that will result in road accident fatality such as speeding, usage of mobile phone and negligence of seatbelts and helmet. In terms of road signs, university students can be exposed more on the different signs available specifically on stopping prohibited and speed limit ends signs which can be confused easily. Educational campaign can emphasise on the importance of road safety and consequences of wrong driving practices to change their behaviour and driving attitudes. Internet can 
be used as a way to advertise road safety as university students are more attentive online. Besides, educating university students is a community process where teachers, traffic polices and authority should contribute to create responsible drivers from an early age with law and regulations enforcement, policy development and implementation, educational programmes and other strategies and interventions to promote and improve road safety.

\section{Conflict of Interests}

The authors declare that there is no conflict of interests regarding the publication of this paper.

\section{Acknowledgement}

The authors are grateful for the financial supports by Research Management Centre, RMC of Universiti Tun Hussein Onn Malaysia, UTHM under Geran Penyelidikan Pascasiswazah, GPPS [vot number: H301] and TIER 1 [vot number: H220].

\section{References}

[1] R. Abd Rahman, M. F. Mohd Nasiruddin, W. M. Lim, M. F. Hassan, N. Mashros, and J. Md Diah, "The 85 th Percentile Speed : the Compliance of Road Users with the $60 \mathrm{~km} / \mathrm{h}$ Speed Limit at U-turn," in International Conference on Business, Science and Technology, 2020.

[2] M. S. Nemmang, R. Rahman, M. M. Rohani, N. Mashros, and J. Md. Diah, "Analysis of speeding behaviour during approaching the U-turn facility road segment based on driving simulation test," in Matec Web of Conferences, 2017, vol. 103, p. 08008, doi: 10.1051/matecconf/201710308008.

[3] R. Abd Rahman et al., "The Compliance of Road Users with the Speed Limit at School Zones on Federal Road FT50 (KM0-KM23)," Int. J. Eng. Adv. Technol., vol. 50, no. 5, pp. 922-929, 2019, doi: 10.35940/ijeat.E1131.0585C19.

[4] E. S. Gharaibeh and A. M. A. Abdo, "Assessment of Traffic Safety and Awareness among Youth in Al-Ahsa Region, Saudi Arabia,” J. Emerg. Trends Eng. Appl. Sci., vol. 2, no. 2, pp. 210-215, 2011.

[5] H. V. Ratna, S. S. Rajesh, A. Jayaram, M. S. Rajanna, P. Venkatesh, and K. Iyengar, "Awareness and behaviour patterns regarding road safety measures among undergraduate students," Int. J. Community Med. Public Heal., vol. 4, no. 4, pp. 944-948, 2017, https://doi.org/10.18203/2394-6040.ijcmph20183952.

[6] Y. B. Elshambaty et al., "Awareness and practice of road safety measures among undergraduate medical students of Al Baha University, KSA,” Int. J. Community Med. Public Heal., vol. 5, no. 10, pp. 4183-4187, 2018, https://doi.org/10.18203/2394-6040.ijcmph20183952.

[7] H. Swami, S. Puri, and V. Bhatia, "Road Safety Awareness and Practices Among School Children of Chandigarh," Indian J. Community Med., vol. 31, no. 3, pp. 199-200, 2006.

[8] A. M. A. Abdo and Y. A. Al-Ibrahim, "Assessment of Traffic Safety and Awareness Among Road Users in Salalah, Sultanate of Oman," Res. J. Appl. Sci. Eng. Technol., vol. 12, no. 5, pp. 574-581, 2016, https://doi.org/10.19026/rjaset.12.2685.

[9] M. A. M. Bilema, M. M. Haurula, and R. Rahman, "The Study of Relationship Between Pedestrian and Safety based on the Theory of Planned Behaviour at Batu Pahat, Johor," MATEC Web Conf., vol. 103, p. 08010, 2017, https://doi.org/10.1051/matecconf/201710308010.

[10] S. Kulanthayan, T. H. Law, R. Abd Rahman, and R. S. Radin Umar, "Seat Belt Use among Car Users in Malaysia," Int. Assoc. Traffic Saf. Sci., vol. 28, no. 1, pp. 19-25, 2004, https://doi.org/10.1016/S0386-1112(14)60088-1.

[11] Australia Department of Infrastructure Transport Regional Development and Local Goverment Austroads, Road Safety Audit. 1994.

[12] R. V. Krejcie and D. W. Morgan, "Determining sample size for research activities,” Educ. Psychol. Meas., vol. 30, no. 3, pp. 607-610, 1970.

[13] A. BrckaLorenz, H. Haeger, J. Nailos, and K. Rabourn, "Student Perspectives on the Importance and Use of Technology in Learning," in Annual Forum of the Association for Institutional Research, 2013.

[14] M. Tavakol and R. Dennick, "Making sense of Cronbach's alpha," Int. J. Med. Educ., vol. 2, pp. 53-55, 2011, https://doi.org/10.5116/ijme.4dfb.8dfd.

[15] R. A. van Griethuijsen et al., "Global patterns in students' views of science and interest in science," Res. Sci. Educ., vol. 45, no. 4, pp. 581-603, 2015, https://doi.org/10.1007/s11165-014-9438-6.

[16] L. Thabane et al., "A tutorial on pilot studies: the what, why and how," BMC Med. Res. Methodol., vol. 10, no. 1, p. 1, 2010, https://doi.org/10.1186/1471-2288-10-1.

[17] K. Goniewicz, M. Goniewicz, W. Pawłowski, and P. Fiedor, "Road accident rates: strategies and programmes for improving road traffic safety," Eur. J. trauma Emerg. Surg., vol. 42, no. 4, pp. 433-438, 2016, https://doi.org/10.1016/j.trpro.2017.05.348. 
[18] K. Choocharukul and K. Sriroongvikrai, "Road Safety Awareness and Comprehension of Road Signs from International Tourist's Perspectives: A Case Study of Thailand," Transp. Res. procedia, vol. 25, pp. 4518-4528, 2017.

[19] H. Mirza and S. Daud, "Study of knowledge, attitude and practice regarding road safety among peri-urban school children," Pakistan J. Med. Heal. Sci., vol. 7, no. 3, pp. 658-661, 2013.

[20] V. Kulkarni, T. Kanchan, C. Palanivel, M. K. Papanna, N. Kumar, and B. Unnikrishnan, "Awareness and practice of road safety measures among undergraduate medical students in a South Indian state," J. Forensic Leg. Med., vol. 20, no. 4, pp. 226-229, 2013, https://doi.org/10.1016/j.jflm.2012.09.022. 